\title{
Difficult endotracheal intubation secondary to tracheal deviation and stenosis in a patient with severe kyphoscoliosis -a case report-
}

\author{
Hyun Jung Kim ${ }^{1}$, Yun Suk Choi ${ }^{1}$, Sang Hyun Park ${ }^{1}$, and Jun-ho Jo ${ }^{2}$ \\ Department of Anesthesiology and Pain Medicine, ${ }^{1}$ Jeju National University School of Medicine, Jeju, \\ ${ }^{2}$ Veterans Health Medical Center, Seoul, Korea
}

We report on a case of difficult endotracheal intubation in a patient with marked tracheal deviation at an angle of 90 degrees combined with stenosis due to kyphoscoliosis with vertebral body fusion. After induction of general anesthesia, a proper laryngeal view was easily obtained using a videolaryngoscope. But a tracheal tube could not be advanced more than $3 \mathrm{~cm}$ beyond the vocal cords due to resistance, despite various attempts, including the use of small size tubes, full rotation of the tube tip, and fiberoptic bronchoscopy. Ultimately, the airway was successfully secured by placing a tube tip above the area of resistance and by additionally packing saline-soaked gauzes around the tracheal inlet to minimize gas leakage and to fasten the tube in the trachea.

Key Words: Intubation, Kyphosis, Scoliosis, Tracheal disease.

Anesthesia can be difficult in patients with severe kyphoscoliosis due to respiratory failure or distortion of the airway anatomy. Several cases about anesthetic management in patients with severe kyphoscoliosis have been reported previously [1-3]. However, there is little information about the airway management of marked tracheal deviation at an angle of 90 degrees combined with stenosis in patients with this kind of disorder.

Corresponding author: Yun Suk Choi, M.D., Ph.D.

Department of Anesthesiology and Pain Medicine, Jeju National University School of Medicine, Aran 13gil 15, Jeju 63241, Korea

Tel: 82-64-717-2029, Fax: 82-64-717-2042

E-mail: solafide5@yahoo.co.kr

Received: June 29, 2015.

Revised: 1st, July 28, 2015; 2nd, August 17, 2015.

Accepted: August 18, 2015.

Korean J Anesthesiol 2016 August 69(4): 386-389

http://dx.doi.org/10.4097/kjae.2016.69.4.386
We would like to report a case of difficult intubation with which we were recently involved.

\section{Case Report}

A 60-year-old woman, $135 \mathrm{~cm}$ in height and $39 \mathrm{~kg}$ in weight, was scheduled for right thyroid lobectomy due to thyroid cancer. She had severe kyphoscoliosis, and surgery was planned under a sternotomy because the thyroid was located below the sternum.

The patient had been taking tiotropium bromide, theophylline, and diuretics for dyspnea. She tolerated light ordinary life activity, but she felt short of breath during exercise and sleeping. At those times, she had been taking inhaled oxygen intermittently. On preoperative examination, she did not complain of respiratory difficulty, and both lungs had clear sounds. However, her neck was very short, and movement limitations were noted (Fig. 1). Chest computed tomography showed severe kyphoscoliosis with destructive vertebral body fusion in the cervical

(c) This is an open-access article distributed under the terms of the Creative Commons Attribution Non-Commercial License (http://creativecommons.org/ licenses/by-nc/4.0/), which permits unrestricted non-commercial use, distribution, and reproduction in any medium, provided the original work is properly cited. 
and upper thoracic spine. The trachea was deviated at an angle of 90 degrees with stenosis just below the deviated area, with the smallest diameter being $6.5 \times 13 \mathrm{~mm}$ (Fig. 2). A pulmonary function test revealed the presence of severely restricted pulmo-

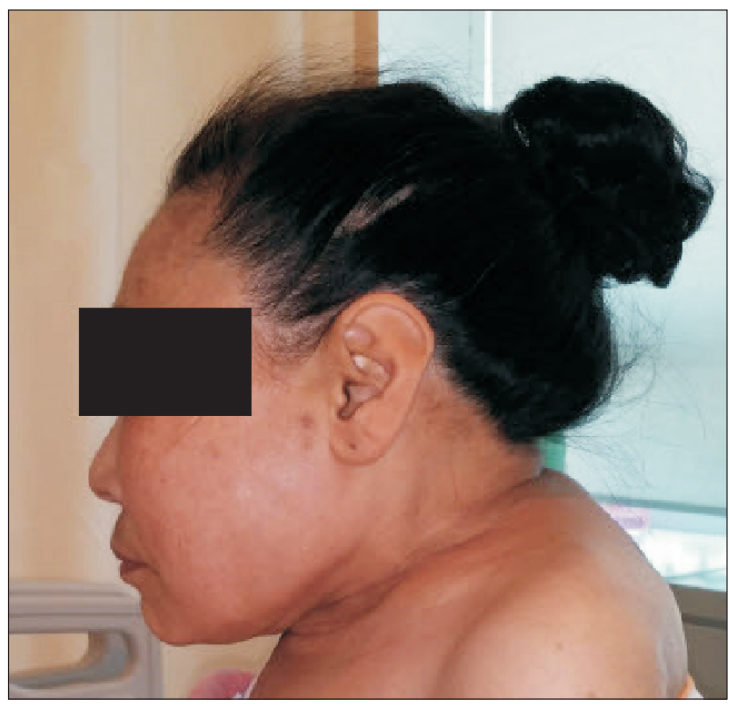

Fig. 1. Lateral view of the face. The neck is very short, and limited movement is noted. nary disease. The measurements demonstrated $\mathrm{FEV}_{1}$ of $0.55 \mathrm{~L}$ (35\% of predicted), FVC of $0.7 \mathrm{~L}$ (35\% of predicted) and $\mathrm{FEV}_{1} /$ FVC 78\%. The arterial blood gas analysis in room air was $\mathrm{PaO}_{2}$ $62.6 \mathrm{mmHg}, \mathrm{PaCO}_{2} 44.8 \mathrm{mmHg}$ and $\mathrm{pH}$ 7.406. Other preoperative laboratory tests including echocardiography and thyroid function test were unremarkable.

When the patient entered the operating room, the routine monitoring systems, including electrocardiogram, pulse oximetry, and non-invasive blood pressure were started. After preoxygenation, general anesthesia was induced with intravenous thiopental $200 \mathrm{mg}$. Proper bag-and-mask ventilation was assured and rocuronium $30 \mathrm{mg}$ was administered to facilitate endotracheal intubation. Under direct laryngoscopy, no laryngeal structures could be identified due to the limited neck movement. Subsequently, we used the Glidescope ${ }^{\circledR}$ videolaryngoscope (Saturn Biomedical Systems Inc., Burnaby, British Columbia, Canada) and were able to obtain a proper laryngeal view. Then, intubation was attempted with a $6.0 \mathrm{~mm}$ cuffed reinforced tracheal tube. However, the tube could not be advanced more than $3 \mathrm{~cm}$ beyond the vocal cords due to resistance despite the good laryngeal view. We attempted intubation again with 5.5 and 5.0 $\mathrm{mm}$ tubes, but the same problem was encountered. Other attempts with various methods, such as full rotation of the tube tip, applying a lubricant, and using fiberoptic bronchoscopy, also
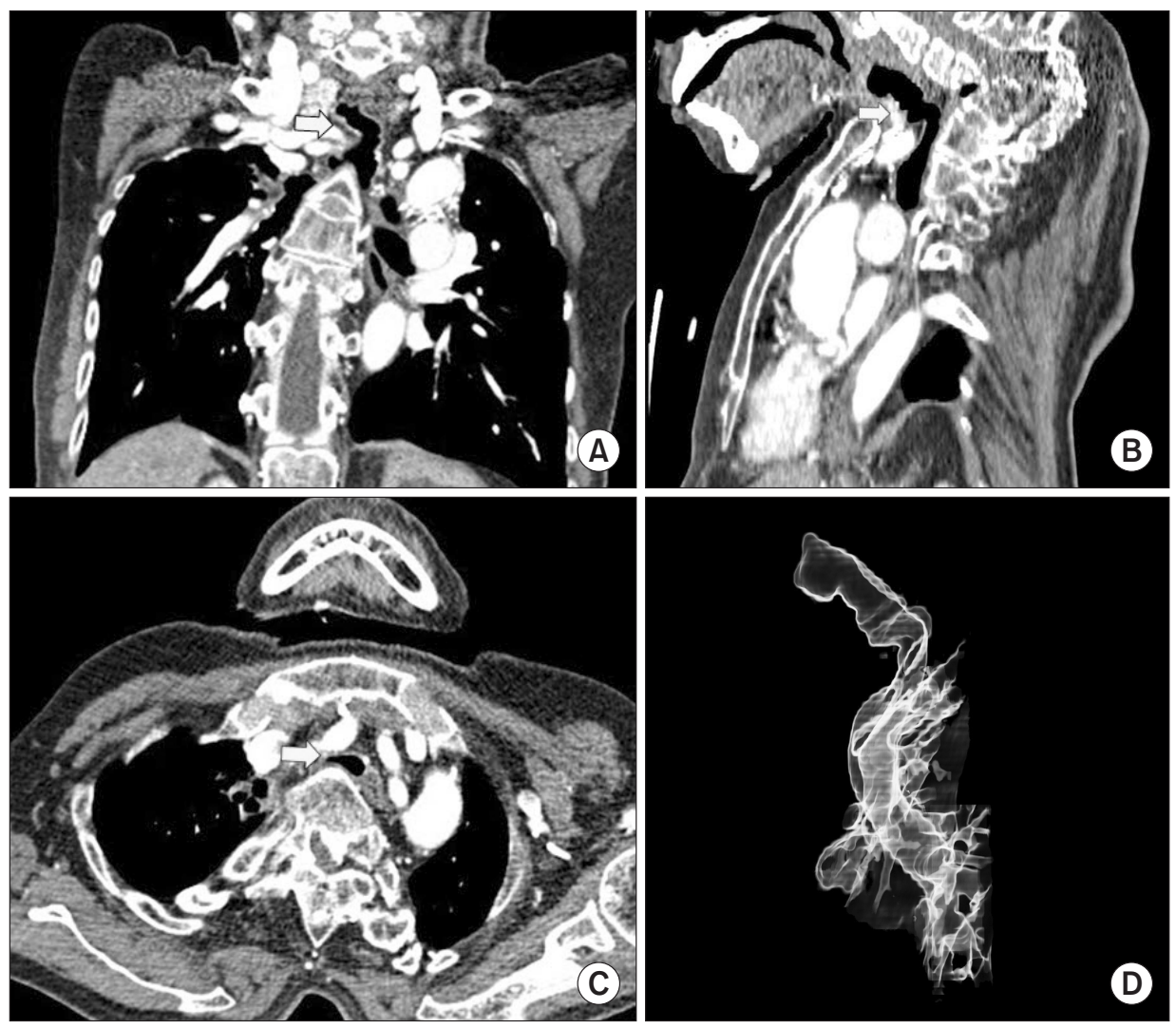

Fig. 2. Preoperative chest computed tomography with coronal plan (A), sagittal plan (B), transverse plan (C) and 3-dimensional lateral image of the trachea $(\mathrm{D})$. The images show severe kyphoscoliosis with destructive vertebral body fusion in the cervical and upper thoracic spine. The trachea was deviated at an angle of 90 degrees with stenosis just below the deviated area, with the smallest diameter being $6.5 \times 13 \mathrm{~mm}$. Arrow: the trachea. 
failed due to same problem.

So we decided to place the tube tip above the area of resistance. Intubation was tried with a $7.0 \mathrm{~mm}$ tube, but the location of the cuff between the vocal cords resulted in gas leakage around the tube despite ballooning. Ultimately, intubation was accomplished with an $8.0 \mathrm{~mm}$ tube without cuff ballooning and saline-soaked gauzes were packed around the tracheal inlet to minimize gas leakage and to fasten the tube in the trachea. Then, positive pressure ventilation could be performed successfully, and dexamethasone $5 \mathrm{mg}$ was administered to minimize airway edema. Anesthesia was maintained with sevoflurane in 50\% oxygen/air, and a ventilator was set to deliver peak airway pressure of $22 \mathrm{~cm} \mathrm{H}_{2} \mathrm{O}$ at a respiratory rate of 12 to 14 breaths/min. The tidal volume was maintained around $300 \mathrm{ml}$, and oxygen saturation by pulse oximetry remained above $95 \%$ throughout the anesthesia.

The operation proceeded under a sternotomy to secure the operative field. Dissecting the thyroid gland was very difficult because it was unusually located on the back of the trachea and adhered to neighboring soft tissues. After the surgery was complete, muscle relaxation was reversed with sugammadex $200 \mathrm{mg}$, and extubation was uneventful. The operation time was $3 \mathrm{~h} 30$ min, and the anesthesia time was $5 \mathrm{~h} 5 \mathrm{~min}$.

After the operation, the patient was transferred to the intensive care unit and was kept for 5 days because of newly developed atelectasis and pleural effusion in the right lung. She was treated with mucolytic agents, bronchodilators, diuretics, and oxygen. Chest physiotherapy such as coughing, deep-breathing exercise, and ambulation was also performed. Her pulmonary condition gradually improved, and she was discharged on postoperative day 20 without sequelae.

\section{Discussion}

Severe kyphoscoliosis is often associated with complicated respiratory problems. The abnormal thoracic cage geometry limits the vital capacity and chest wall compliance, generally resulting in restrictive respiratory disease. This induces alveolar ventilation/perfusion mismatch, worsening of gas exchange, and desaturation $[3,4]$. Pulmonary hypertension is the result of increased pulmonary vascular resistance caused by compressed lung vasculature and the response to arterial hypoxia. Pulmonary infection is also frequent because of poor cough [5]. In the present case, the patient complained of dyspnea intermittently, the arterial blood gas analysis showed mild hypoxemia, and pulmonary function tests revealed the presence of severely restrictive pulmonary disease. However, the patient had been taking medications for dyspnea, and the disease was well-controlled without pulmonary hypertension.

Rather, an important issue in this patient was the anatomic deformity of the airway, which was anticipated to make endotracheal intubation difficult $[2,4]$. First, her neck was very short, and her neck movement was limited due to kyphoscoliosis with destructive vertebral body fusion. We could not identify any laryngeal structures under direct laryngoscopy. This problem was overcome by using a relatively new airway device: the Glidescope $^{\circledR}$ videolaryngoscope. Compared with direct laryngoscopy, the Glidescope ${ }^{\circledR}$ videolaryngoscope has been shown to provide a superior laryngoscopic view for endotracheal intubation [6,7]. We were able to obtain a proper laryngeal view using this device and could insert a tracheal tube between the vocal cords easily.

However, the tracheal deformities of the patient presented difficulties. Her trachea was severely deviated to an angle of 90 degrees and stenosed below the deviated area. The tracheal deviation could be caused by various factors including a thyroid goiter [8,9], a tumor in the neck and thorax [10], trauma [11], congenital cardiac disease [12], lung collapse [13] and, like this patient, spinal deformities such as kyphoscoliosis [2,4]. Whatever the cause may be, in most previous reports, authors tried to advance a tracheal tube below the deviated area and the results were successful $[2,8,9,14]$. But Davies [1] had reported a case of intubation failure in a patient with combination of marked tracheal deviation and a tracheal diverticulum. In that case, the airway was secured using a laryngeal mask airway during the operation. In the present case, we also tried insert a tracheal tube through the deviated area with various methods. But the tube could not be advanced more than $3 \mathrm{~cm}$ beyond the vocal cords despite the proper laryngeal view. The combination of marked tracheal deviation and stenosis could account for the difficulty. The use of supraglottic airway devices was not considered in this patient because they could have been relatively unsafe during the sternotomy and dissection of the thyroid gland which was unusually located on the back of the trachea. In addition, if the supraglottic airway device needed to be adjusted, it might have been difficult because the patient's neck was very short. Therefore, we ultimately decided to place the tube tip above the resistive tracheal area and to additionally pack saline-soaked gauzes around the tracheal inlet to minimize gas leakage and to fasten the tube in the trachea. Then, mechanical ventilation was performed successfully, and the operation proceeded uneventfully.

In conclusion, severe kyphoscoliosis could be associated with difficult airway management due to a distorted airway anatomy. If a tracheal tube could not advance easily in a patient with this disease, one should not force the passage of a tube against resistance. Depending on the surgical procedure, using supraglottic airway devices or positioning a tracheal tube above the area of resistance may be useful alternatives. 


\section{Acknowledgments}

This work was supported by the research grant of Jeju National University in 2014.

\section{ORCID}

Hyun Jung Kim, http://orcid.org/0000-0002-4852-7165

\section{References}

1. Davies R. Difficult tracheal intubation secondary to a tracheal diverticulum and a 90 degree deviation in the trachea. Anaesthesia 2000; 55: 923-5.

2. Kanri T, Watanabe K, Yoshikawa T, Suzuki T, Sano K, Kitano T, et al. Experiences in general anesthesia of patients with scoliosis presupposed to have difficulties in airway maintenance. Shigaku 1990; 78: 377-82.

3. Kundra P, Joseph A, Kumar S, Sai Chandran BV. Double-lumen tube for ventilation in severe kyphoscoliosis. J Anesth 2008; 22 : 317-21.

4. Al-Kattan K, Simonds A, Chung KF, Kaplan DK. Kyphoscoliosis and bronchial torsion. Chest 1997; 111: 1134-7.

5. Tsiligiannis T, Grivas T. Pulmonary function in children with idiopathic scoliosis. Scoliosis 2012; 7: 7.

6. Cooper RM, Pacey JA, Bishop MJ, McCluskey SA. Early clinical experience with a new videolaryngoscope (GlideScope) in 728 patients. Can J Anaesth 2005; 52: 191-8.

7. Kim JT, Na HS, Bae JY, Kim DW, Kim HS, Kim CS, et al. GlideScope video laryngoscope: a randomized clinical trial in 203 paediatric patients. Br J Anaesth 2008; 101: 531-4.

8. Ghai A, Hooda S, Wadherra R, Garg N. Gross tracheal deviation: airway challenges and concerns--two case reports. Acta Anaesthesiol Belg 2011; 62: 203-6.

9. Mallat J, Robin E, Pironkov A, Lebuffe G, Tavernier B. Goitre and difficulty of tracheal intubation. Ann Fr Anesth Reanim 2010; 29 : 436-9.

10. Kambayashi T, Terada Y. Giant hemangioma in the neck extending into the mediastinum required a second operation after 39 years; report of a case. Kyobu Geka 2005; 58: 841-4

11. Oka Y, Nishijima J, Azuma T, Inada K, Miyazaki S, Nakano H, et al. Blunt thyroid trauma with acute hemorrhage and respiratory distress. J Emerg Med 2007; 32: 381-5.

12. Greene A, Gaver R. Tracheal deviation secondary to massive cardiomegaly in a two month old child with newly diagnosed total anomalous pulmonary venous return. J Clin Anesth 2013; 25: 602-3.

13. Graetz K, Hassan T. Tracheal deviation as a sign in ill patients: beware ipsilateral pathology. J Accid Emerg Med 1998; $15: 297$.

14. Crabb IJ. Anterior deviation of the trachea. Anaesthesia 2001; 56: 284-6. 